\title{
Shame, Guilt, Narcissism, and Depression: Correlates and Sex Differences
}

\author{
Fred Wright, $\mathrm{PhD}$ \\ John Jay College of Criminal Justice \\ John O'Leary, PhD \\ William Alanson White Institute \\ Joseph Balkin, PhD \\ John Jay College of Criminal Justice
}

\begin{abstract}
This study examines the relationships between shame, guilt, narcissism, and depression and the gender differences connected with these states. We hypothesize that shame would be a more powerful contributor to narcissism and depression than guilt and that women would score higher in shame, higher in depression, and lower in narcissism than men. The Adapted Shame/Guilt Scale, the Narcissistic Personality Inventory, and the Self-Rating Depression Scale were administered to male and female undergraduates.

The results show that shame plays an important role in both narcissism and depression, and that its role in depression is stronger than that of guilt. It was also concluded that men are more prone to narcissism and women to depression, and sex differences related to shame and guilt are linked to specific situations and self-images. Implications for reatment are also noted.
\end{abstract}

Recently, there has been a resurgence of clinical and theoretical interest in the superego. One reason is the expansion of psychoanalytic interest into new territories where superego deficits are paramount (i.e., the preoedipal conditions). Kernberg (1984), for example, stated that the two most important considerations in the treatability of borderline and narcissistic states is the quality of the patients' object relations and the relative integration of their superegos.

Requests for reprints should be sent to Fred W/right, PhD, Department of Psychology, John Jay College of Criminal Justice, 445 West 59th Street, New York, NY 10019. 
The second factor promoting a new interest in the superego is the increasing emphasis on the role of shame in at wide range of psychopathology. Ccnceptually, shame has been linked to a historically neglected structure witt in the superego, the ego-ideal. In his paper, "On Narcissism," Freud (1914) put forward the idea that there is an agency of the mind that watches the ego and compares it with an ideal standard. In Group Psychology and the Analysis of the Ego, Freud (1921) further developed this notion and emphasized the positive and rewarding aspect of the relationship between the ego and its ideal.

Freud failed to fully develop this concept, however. Instead, he began to highlight the superego as heir to the oedipal phase with a distinct emphasis on the role of internalized parental prohibitions. Transgressions of these prohibitions led to attacks on the ego in the form of guilt. With the development of the structural point of view (Freud, 1923), guilt and its vicissitudes became the principal consideration in the further elaboration of superego function. Guilt, thereafter, played a dominant role in the understanding of psychopathology, particularly for depression and obsessive-compulsive neurosis.

It remained for other analysts to take up the notion of the ego-ideal and relate it to the experience of shame. Piers and Singer did this in 1953 when they published their classic monograph, Shame and Guilt: $A$ Psychoanalyiic and Cultural Study. They clearly defined shame as a failure to live up to the ego-ideal and distinguished it from guilt which resided in the superego proper. Other writers on the role of the superego (e.g., Jacobson, 1964) have continued this line of thought.

For Helen Block Lewis (1971), differences in routes of identification determine whether the shame or guilt state will be stirred. As she stated it, "identification with the threatening parent stirs an 'internalized threat' which is experienced as guilt. Identification with the beloved or admired ego-ideal stirs pride and triumphant feeling; failure to live up to this internalized admired imago stirs shame" (p. 23).

Thus, it is evident that there has been a slow but steady evolution of a dichotony between these two superego-related affective states, with increasing interest being shown in the role of shame. Moreover, recent psychoanalytic writers have noted that the shame experience is associated with a number of clinically relevant issues. These include narcissism (Broucek, 1982; Lewis, 1983; Morrison, 1983; O'Leary \& Wright, 1986; Wurmser, 1981) and depressicn (Hoblitzelle, 1982; Izard, 1972; Lewis, 1986), and possibly gender (Lewis, 1975; O'Leary \& Wright, 1986). Many writers, in fact, contend that shame is the "keystone affect" in narcissism (e.g., Broucek, 1982; Kinston, 1983; Morrison, 1983). Broucek (1982), for example, said that "shame experiences disrupt the silent automatic functioning of the sense of self, and shame is therefore considered to be the basic form of unpleasure in disturbances of narcissism" (p. 376).

We agree that shame is a central affect in narcissistic disorders but we think 
there is often an inverse relationship between the two experiences. That is, many individuals high in conscious grandiosity-a central feature of pathological narcissism - will tend to report few shame feelings. Shame for these patients will be denied or dissociated. The opposite will hold for a second type of narcissistic disorder. These latter individuals will have intense, conscious shame experiences and will dissociate grandiose and other narcissistic feelings.

Other writers (e.g., Modell, 1984) have emphasized guilt in their discussions of narcissism and do not mention shame at all. One goal of our study, therefore, is to address an imbalance in the literature.

Shame and guilt have also been tied to disorders of depression by psychoanalysts. Lewis (1986) emphasized the role of shame in depression and Hoblitzelle (1982), in an empirical study, found shame correlated significantly with depression. On the other hand, guilt's role in depression has been stressed by psychoanalytic writers since Freud (see Blatt, 1974, for a review of this literature). In his classic paper, "Mourning and Melancholia," Freud (1917) clearly spelled out the role of guilt and self-reproach. According to Prosen, Clark, Harrow, and Fawcett (1983), this prototype of depressive states, in which guilt is defined as an almost universal feature, has gone unchallenged until receritly. Interestingly, in a comprehensive empirical study of hospitalized depressives by Prosen et al., guilt was far less prominent than was low selfesteem. Indeed, guilt scores failed to discriminate the depressed patients from the schizophrenic patients in their sample. Thus, another goal of our study is to investigate the relationship between these superego states and depression, most especially to replicate Hoblitzelle's correlation between shame and depression.

Sex differences in the affects of shame and guilt and proneness to emotional disorder have been noted by a number of authors. Lewis (1976), for example, suggested that men are more apt to feel guilt, whereas women are more prone to shame feelings. She attributes these differences to socialization and identification processes which train men toward aggression. This leads to guilt. Women, according to Lewis, tend to be more focused on relationships, which, in turn, makes them more prone to shamelike experiences.

Although there are relatively few studies that test this hypothesis directly, there are some that bear on it indirectly. Miller (1985), for example, in his study of "embarrassability", a variant of shame, found women to be more embarrassable than men.

A.khtar and Thompson (1982), in their classic article on the Narcissistic Personality Disorder, noted that most of the narcissistic patients reported on by clinicians are men, and they wonder if the development of the narcissistic personality is intertwined with male psychosexual development.

Other researchers have shown women to be more prone to depression than men (Radloff, 1986; Tarnower \& Humphries, 1969). Therefore, a third goal of this study is to compare and contrast the sexes on the variables of shame, 
guilt, narcissism, and depression to see if further support for such differences could be found.

To summarize, three major hypotheses are offered here:

1. Both shame and guilt will be related to narcissism. More specifically, shame will have an inverse relationship to narcissism.

2. Although both shame and guilt will be related to depression, shame will prove to be more strongly related to depression.

3. There will be significant gender differences on each of the major variables of this study; specifically, women will score significantly higher on measures of shame and depression than men, whereas men will sccre significantly higher on measures of guilt and narcissism than women.

\section{METHOD}

The adapted Shame/Guilt Scale (Hoblitzelle, 1982), the Self-Rating Depression Scale (Zung, 1965), and the Narcissistic Personality Inventory (Raskin \& Hall, 1979) were each administered to 100 college students (62 women and 38 men). These students came from diverse ethnic backgrounds and were drawn from a large urban university population. The men ranged in age from 18 to 46 years with a mean age of 25 , whereas the women ranged from 18 to 53 years with a mean age of 28 . Questionnaires were administered ${ }^{\prime}$ in groups of 10 to 20 students, and one of the investigators was present during the atdministration to answer any questions.

The Adapted Shame/Guilt Scale consists of 30 adjectives considered to be either shame or guilt words. Subjects were asked to rate how well each of the adjectives described them on a 7-point scale. In computing shame and guilt scores for the subjects in this study, only adjectives loading above .50 according to Hoblitzelle's factor analyses were used. Thus, 10 adjectives were used to derive the shame scores and 12 adjectives were used to derive the guilt scores. Hoblitzelle found the alpha reliability coefficient to be .86 for the 10 shame words and .88 for the 12 guilt words. The internal validity for the Adlapted Shame/Guilt Scale was quite high. Construct validation was also obtained for the shame words, but not the guilt words.

The Self-Rating Depression Scale consists of 20 statements which assess clinical symptoms of depression such as fatigue, appetite loss, sleep disturbance, irritability, hopelessness, and sadness. Subjects were asked to rate eac.1 of the statements as to how it applied to them at the time of testing in the

\footnotetext{
'We are aware that self-report paper-and-pencil instruments tend more often to tap conscious processes and may not allow for a complete assessment of complex affective states such as shame and guilt. These limitations seem inevitable, however, as clinical concepts are translated ints systematic research.
} 
following four quantitative terms: none or a little of the time, some of the time, a good part of the time, or most of the time. Zung (1969) reported evidence showing concurrent validity for the Self-Rating Depression Scale, but no evidence on the reliability of this scale has been reported in the literature.

The Narcissistic Personality Inventory has 54 forced-choice items, and a possible range of scores from 0 to 54 . High scores indicate high narcissism. The item content reflects the Diagnostic and Statistical Manual of Mental Disorders (3rd ed.; DSM-III; American Psychiatric Association, 1980) description of the narcissistic personality disorder. An example of one of the forcedchoice items is:

a. I am much like everybody else.

b. I am an extraordinary person.

The inventory can be further broken down into seven subscales. The items forming these subscales were derived from theoretical as well as content analyses and were found to be a good. fit. The seven subscales are Leadership, Exhibitionism, Exploitativeness, Specialness (we coined the term for this subscale because the authors of the inventory have left it unnamed), Entitlement, Grandiosity, and Self-Admiration. Raskin and Hall (1981) provided eviderice for the construct validity of this inventory and also reported an alpha reliability coefficient of .86 .

\section{RESULTS}

\section{The Fiole of Shame and Guilt in Narcissism and Depression}

Pearson product-moment correlations between scores on the Adapted Shame/ Guilt Scales, the Narcissistic Personality Inventory, and the Self-Rating Depression Scale for men, women, and combined groups are presented in Table 1.

Ar inspection of the combined scores in Table 1 shows some noteworthy relationships between shame, guilt, narcissism, and depression. For instance, a moderate but significant negative correlation between shame and narcissism, $r=-.21, p<.05$, as well as a small positive association between guilt and narcisisism, $r=.17, p<.05$, is shown. The association between guilt and narcissism, however, is due exclusively to the correlation between guilt and narcissism for men as examination of Table 1 shows. These results, therefore, provide partial support for the first hypothesis of this study which states that shame and guilt will be related to narcissism.

The relationship depression has with shame, guilt, and narcissism can also be seen by inspection of the combined scores in Table 1. The correlation between depression and shame is highly significant, $r=.49, p<.001$, whereas 
TABLE 1

Correlation Matrix of Scores for the Adapted Shame/Guilt Scale, the Narcissistic Personality Inventory, and the Self-Rating Depression Scale

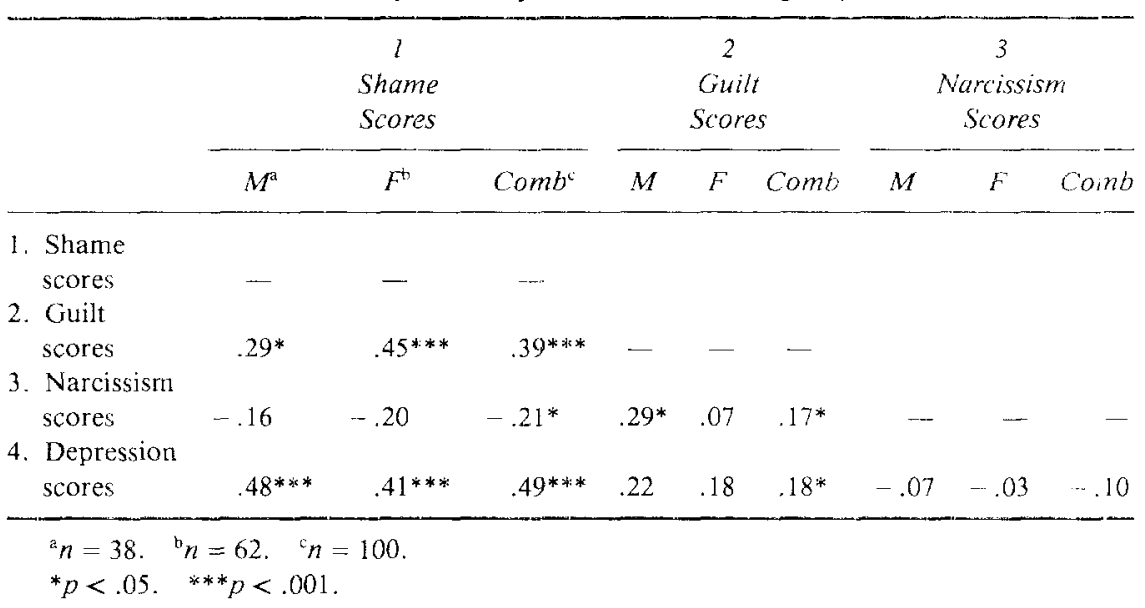

the relationship between depression and guilt is lower but still significart, $r=.18, p<.05$. These findings support in a striking manner the second hypothesis that shame and guilt will both be related to depression, with shanie having a stronger relationship with depression than guilt has with depression.

\section{Sex Differences}

As just noted, narcissism and guilt have a moderate and positive association for men, $r=.29, p<.05$, whereas for women there is no relationship. Further assessment of differences between men and women on the variables of shame, guilt, narcissism, and depression was accomplished by computing means ard standard deviations on each of the four measures for both men and women. Tests were applied to these data and the results are presented in Table 2.

Examination of Table 2 indicates that men $(M=20.92)$ scored significant y higher on narcissism than did women $(M=17.27), t(98)=2.39, p<.05$, and that women $(M=39.73)$ reported more depression than men $(M=36.26)$, $t(98)=2.38, p<.05$. No significant differences were obtained between the sexes on the shame and guilt measures, however. These findings provided oniy partial support for the third hypothesis in this study, which was that men and women would differ on shame, guilt, narcissism, and depression.

The authors of the Narcissistic Personality Inventory identified seven subscales that make up this measure of narcissism. The breakclown of the instrument in this fashion provided the opportunity to further explore sex differences. Pearson product-moment correlations between subjects' scorts on the narcissism subscales, and their shame and guilt scores were calculated for each sex. The results are reported in Table 3. 
Examination of Table 3 shows there were a number of instances where correlations differed for men and women. These were transformed to Fisher's $Z$, a normalizing transformation of Pearson product-moment correlations, prior to testing for differences. Significant differences were found between the sexes on two of the correlations under analysis, those between Exploitativeness and Shame, $Z=-2.52, p<.05$, and Specialness and Guilt, $Z=2.11, p<.05$.

There are two other instances where the differences between men and women are worthy of note, even though the differences did not achieve significance according to the Fisher $Z$ method. As Table 3 shows, there were significant inverse correlations for wornen between Leadership and Shame, $r=-.30, p<.01$, and Grandiosity and Shame, $r=-.30, p<.01$, whereas for the men there were no significant relationships on these items.

\section{DISCUSSION}

\section{Shame, Guilt, and Narcissism}

Evidence has been presented confirming the hypothesis that there is a relationship between the effects of shame and guilt and narcissistic experience, and, more specifically, that shame and narcissism are inversely related. This latter notion was derived from an earlier article (O'Leary \& Wright, 1986) where, based on clinical and theoretical accounts, it was concluded that this kind of relationship would occur in narcissistic disorders. It was posited in this earlier article that there are at least two patterns that shame and narcissism take in pathological narcissism: one in which narcissistic experience is in the forefront of consciousness wherein shamelike feelings are denied or repressed and an opposite pattern where shame feelings are more conscious and narcissistic feelings are dissociated. The negative correlation between shame and narcissism supports this formulation. Although unconscious processes were not measured, those subjects who scored high on the Narcissism scale tended to score low on the shame scale. Conversely, those who

TABLE 2

Means and Standard Deviations for Women and Men on Shame, Guilt, Narcissism, and Depression Scales

\begin{tabular}{lcccr}
\hline & \multicolumn{2}{c}{ Female $^{*}$} & & Male $^{b}$ \\
Variable & $M$ & $S D$ & $M$ & $S D$ \\
\hline Shame & 33.98 & 9.34 & 31.18 & 8.95 \\
Guilt & 22.60 & 7.34 & 22.95 & 7.78 \\
Narcissism & 17.27 & 5.13 & $20.92^{*}$ & 9.15 \\
Depression & 39.73 & 7.31 & $36.26^{*}$ & 6.64 \\
\hline
\end{tabular}

${ }^{\mathrm{a}} n=62 . \quad{ }^{\mathrm{b}} n=38$.

$*_{p}<.05$. 
TABLE 3

Correlations Between Shame and Guilt Scores and Subscales of the Narcissistic Personality Inventory

\begin{tabular}{lcccc}
\hline & \multicolumn{2}{c}{ Shame } & & Guilt \\
\cline { 5 - 5 } NPI Subscale Scores & Men $^{\mathrm{a}}$ & Women $^{b}$ & Men & Women \\
\hline 1. Leadership & -.10 & $-.30^{* *}$ & .06 & .03 \\
2. Exhibitionism & .16 & .13 & .26 & .17 \\
3. Exploitativeness & $-.35^{*}$ & $.17^{\mathrm{c}}$ & .20 & .11 \\
4. Specialness & -.25 & -.21 & $.28^{*}$ & $.15^{\circ}$ \\
5. Entitlement & .06 & .18 & .25 & $.22^{*}$ \\
6. Grandiosity & -.07 & $-.30^{* *}$ & .22 & -.05 \\
7. Self-Admiration & -.20 & -.12 & .17 & -.02 \\
\hline
\end{tabular}

${ }^{\mathrm{a}} n=38 .{ }^{\mathrm{b}} n=62$. "These were transformed to Fisher's $Z$, a normalizing transformation of Pearson product-moment correlations prior to testing for differences. The only differences of significance were at the .05 level

$* p<.05 . \quad * * p<.01$

scored low on the Narcissism scale tended to score high on the Shame scale.

Several writers (e.g., Kernberg, 1975; Reich, 1960) supported the part of this formulation that indicates narcissism will be in the forefront of conscio as experience while shame will be repressed. Their central point is that narcissistic behavior is a defense against images of the self as worthless and inferior. The defense, of course, is designed to eradicate these self-images and the acconpanying feelings of shame and humiliation, thus producing the inverse relationship reported in this study.

The second part of the aforementioned formulation refers to the person who dissociates narcissistic experience and suffers from, and is aware of, low self-esteem. Broucek (1982) indicated that this is the brand of narcissism that Kohut is talking abolıt for the most part.

It was also argued in our article (C'Leary \& Wright, 1986) that men ard women would tend to differ on this dynamic. Specifically, for narcissistically inclined women, shame feelings would be more conscious and narcissistic experience more unconscious. For narcissistic men, narcissism would dominate while shame would be dissociated.

The findings derived from the correlations of the Narcissism subscales with shame and guilt provide some support for these notions and help to speci:y the sources of the differences. There were significant inverse correlations $b_{2}$ tween shame and leadership and shame and grandiosity for women, but not for men. Men, on the other hand, produced significant negative correlations between shame and exploitativeness, whereas women had a nonsignificant but positive correlation between these two variables. This gender difference was significant when a Fisher $Z$ test was applied.

These results indicate that, at least for some women (possibly those with 
problems related to narcissism), shame experiences and aspirations toward leadership and grandiosity (traits associated with narcissism) are not compatible. A viable interpretation is that shame-prone women find it difficult to assert themselves and strive for dominance and leadership. This pattern doesn't hold for men. However, the significant negative correlation for men between shame and exploitativeness (another trait associated with narcissism) indicates that shame and exploitative behavior tend to be diverging experiences for many men. This suggests a different kind of narcissistic configuration for men. Narcissistically inclined men who engage in exploitative behavior will tend not to consciously experience shame.

The evidence also shows a different pattern for men and women regarding the relationship between guilt and narcissism. There is a significant positive correlation between narcissism and guilt for men, but not for women. Men have a number of positive correlations between the subscales of narcissism and guilt, while women have more random patterns on these correlations. Further, and in line with this pattern, a significant difference between men and women on the guilt-specialness correlation was obtained when a Fisher $Z$ test of differences was applied. Men show a positive relationship between guilr and specialness whereas women present a negative association between these two factors. The results suggest that feeling special is accompanied by guilt for men, but this is not the case for women.

A second possibility is that the affect of guilt fits with narcissistic behavior for men because guilt implies a sense of power (even if it is the power to do "evil"), and it also implies a sense of autonomy with its emphasis on freely chosen action (i.e., the guilty person always believes he or she could have chosen differently). Thus, phenomenologically, guilt and narcissism support and reinforce each other.

The findings in this study are intriguing in light of Lewis's (1976) discussion of sex differences in superego style. She indicated that men will be more prone to guilt feelings and women more prone to shame feelings. The comparisons of male and female scores on the shame and guilt scales used in this study do not support Lewis's argument in that the differences between the two groups were not significant. However, the correlational findings from our study do show different patterns for men and women between shame and guilt, at least where subcategories of narcissism are concerned.

Striving to differentiate between men and women on shame and guilt through comparisons on these affects alone is not likely to be meaningful. Rather, shame and guilt feelings appear to be linked to specific activities as well as particular personality characteristics, and these, in turn, may interact with gender. It may be necessary in future research to specify the activities and/or personality traits that will be related to shame and guilt to see if gender differences occur in the context of such interactions. For example, the research reported here suggests that the relationship between shame experiences and the image of one's self behaving in an exploitative fashion will 
differ, with women more apt to feel shame over such a self-image whereas men will not.

\section{Shame, Guilt, and Depression}

One of the goals of this study is to examine the relationship of shame and guilt to depression. The hypothesis that both shame and guilt would be significantly related to depression, and that shame would have a stronger re ationship with depression was supported. The correlations between shame and depression are a good deal stronger than the correlations between guilt and depression. This suggests that shame is a more central affective experience for depressed people than guilt. This is noteworthy because psychoanaly:ic clinicians, as noted earlier, have tended to think of guilt as the central affect in depression. Our finding replicates the earlier work of Hoblitzelle (1982) who obtained a similar correlation between the Adapted Shame/Guilt Scele shame scores and the Self-Rating Depression Scale, $r=.42, p<.001$. These results also confirm the Prosen et al. (1983) findings where low self-esteem emerges as more uniform and important for depressed patients than does guilt.

\section{Gender Differences in Narcissism and Depression}

The final observation to be made in this discussion has to do with the significantly different scores men and women achieved on the measures of narcissism and depression, with men scoring higher on narcissism and women higher on depression. There is strong support in the literature for the finding that women tend to be more prone to depression than men. The idea that men are more prone to narcissism has been less noted, but there have been such observations (e.g., Akhtar \& Thompson, 1982; Blatt \& Shichman, 1982).

In order to account for these gender differences we are presenting the following hypothesis: Men and women tend to differ in the way they cope with assaults on their self-esteem. Women are more apt to experience them consciously and directly, whereas men are more prone to deny and deferid against lowered self-esteem through narcissistic behavior. Along with Blatt (1983), we view narcissistic behavior as a complex set of compensatory defens is designed to ward off depression that is stimulated by thoughts and feelings of being unloved, unwanted, and unacceptable. Men are more inclined 10 handle feelings of inferiority this way than are women.

Why is this the case? We believe complex socialization and identificaticn processes are at play. These processes more often lead women to resolve difficulties in interpersonal relations by containing feelings inside themselves or turning against themselves, whereas many men resort to narcissistic solutions to their problems. These solutions include assumptions of entitlement, selfaggrandizement, overcompensation, and projection.

These and related matters have been discussed in a thoughtful article try 
Blatt and Shichman (1983). These authors described two basic personality configurations, each having its own experiential mode, as well as form of cognition, defense, and adaptation. The development of stable and meaningful interpersonal relatedness defines one configuration, called an anaclitic deveiopmental line. The development of a consolidated and differentiated identity and self-concept, called an introjective developmental line, defines the second configuration.

They further indicated that different types of psychopathology are distorted exaggerations of either one of these configurations, and that disorders of the introjective configuration occur with greater frequency in men, whereas disorders of the anaclitic configuration occur with greater frequency in women.

Blatt and Shichman (1983) explained these gender differences by pointing out that Western society places more emphasis on the need for self-definition for men and on the capacity for relatedness for women. May (1980) and Gilligan (1982) presented similar argurnents. Blatt and Shichman also referred to developmental processes that differentially affect the sexes. They noted the dernand for women to wean from the primary relationship with mother in order to find an appropriate object for affection. Men, on the other hand, must first move from the primary relationship with mother to identification with a male figure before finding an appropriate object for affection. These developmental lines lead to different vulnerabilities and sensitivities for men and women.

\section{Treatment Implications ${ }^{2}$}

These matters have implications for treatment. First, clinicians might keep in mind that patients' narcissism may well be behavior designed to avoid dissociated or anticipated shame experiences. Thus, the analyst may need to attend more to the underlying shame than the more vivid manifest behavior. Second, it may be helpful to the depressed patient for the analyst to be particuiarly alert to shame and shame-related experiences, because these might be the kinds of experiences that are helping to fuel the depression. Third, differentiating shame from guilt may also be useful, keeping in mind that patients' preoccupations with guilt might be a defense against more primary, and consequently, more threatening, underlying shame experiences.

We found that guilt is more accessible than shame for most patients. Guilt is relieved by confession whereas shame tends to stay hidden. When it does come forth, the expression of shame does not necessarily bring relief. A therapist's exclusive reliance on empathy may be read by the patient as, "Now, even you know my shame." This might be the basis of the frequent complaint

'The following discussion should be conside:ed in light of the fact that the subjects of the resectrch presented in this article were drawn from a college student population rather than a population of psychiatric patients. 
heard from patients, "If I tell you these things I'll only feel worse." Painf 11 shame experiences may require a more active stance by the therapist. Lewis (1971) emphasized the importance of communicating acceptance in the sen:e of "positive regard" to the shamed person. Beck, Rush, Shaw, and Emery (1979), in their treatment of depression, recommended actively counterirg the false beliefs that are latent in the disorder. Some shame experiences maly sirnilarly require such an active therapeutic posture.

It seems clear enough that men and women will often differ in the difficulties they present, in their gender-related perceptions, as well as their transferences. Narcissistic men, for example, may experience the exposure attendant to therafiy as particularly shameful and disorienting. They may employ compensatory defenses which require extraordinary tact on the part of the therapist. Such men may be particularly ashamed of their capacity to be ashamed. As a result, they can present a very tough façade. The therapist needs to be on guard lest he $\mathrm{cr}$ she underestimate how vulnerable these men can be.

Complications are particularly likely to arise in cross-sex dyads (men treating women, women treating men). Our data lead us to believe that the arenas where shame is likely to be expressed vary significantly according to gender. For exarr-ple, will it be more shameful for narcissistic male patients to be in treatment with female therapists? Will they feel twice humiliated? Once because they are in treatment; twice because a normally subordinate class member (woman) has been raised to a superior position (therapist)? Is the patient likely to mention these feelings if they do exist? Or will their shame about such obviously sexist beliefs keep them underground, further deepening their narcissistic shell?

Similar dynamics may be at work with depressed female patients and their male therapists. If shame is indeed central to the workings of depression, how is this complicated by working with a male therapist? Experience tells us that certain topics are harder to talk about with the opposite sex. For example, women often have difficulty in discussing material pertaining to the inside; of their body with a man. Add to this the power differential that exists in this society between men and women. This power differential is particularly obvious in mental hospitals where, generally speaking, doctors are men and nurses are women. Hence, a hospitalized depressed female patient has two barriers to overcome in engaging her male therapist--the gender difference itself with the accompanying subjective experiences, as well as salient statu:s differences. These differences are particularly likely to magnify the patient's experience of shame in the context of a disorder already riddled by shame experiences. Our position is that the therapist needs a vocabulary for antici.. pating these issues. Shame is a marker toward such a vocabulary.

\section{ACKNOWLEDGMENTS}

The assistance of Wendy Hoblitzelle and Helen Block Lewis in helping to select instruments for this article is gratefully acknowledged. 
We also express our appreciation for suggestions made by Helen Block Lewis on an earlier version of this article.

\section{REFERENCES}

Akhtar, S., \& Thompson, J. (1982). Overview: Narcissistic personality disorder. American Journal of Psychiatry, 139(1), 12-20.

American Psychiatric Association. (1980). Diagnostic and statistical manual of mental disorders (3rcl ed.). Washington, DC: Author.

Beck, A. T., Rush, A. J., Shaw, B. F., \& Emery G. (1979). Cognitive therapy of depression. New York: Guilford.

Blatt, S. J. (1974). Levels of object representation in anaclitic and introjective depression. The Psychoanalytic Study of the Child, 29, 107-157.

Blatt, S. J. (1983). Narcissism and egocentrism as concepts in individual and cultural development. Psychoanalysis and Contemporary Thought, 6(2), 291-303.

Blatt, S. J., \& Shichman, S. (1983). Two primary configurations of psychopathology. Psychoancilysis and Contemporary Thought, 6(2), 187-254.

Broucek, F. J. (1982). Shame and its relationship to early narcissistic development. The International Journal of Psycho-Analysis, 63, 3691-378.

Freud, S. (1914). On narcissism: An introduction. S.E., 14, 73-102.

Freud, S. (1917). Mourning and melancholia. S.E., 14, 243-258.

Freuc., S. (1921). Group psychology and the analysis of the ego. S.E., 18, 69-143.

Freuc., S. (1923). The ego and the id. S.E., 19, 12-59.

Gilligan, C. (1982). In a different voice. Cambridge, MA: Harvard University Press.

Hoblitzelle, W. (1982). Developing a measure of shame and guilt and the role of shame in depression. Unpublished predissertation, Yale University, New Haven, CT.

lzard, C. (1972). Patterns of emotion: A new analysis of anxiety and depression. New York: Aciademic.

Jacobson, E. (1964). The self and the object world. New York: International Universities Press. Kernberg, O. (1975). Borderline conditions and pathological narcissism. New York: Aronson. Kernberg, O. (1984). Severe personality disorders. New Haven, CT: Yale University Press.

Kinston, W. (1983). A theoretical context for shame. The International Journal of Psycho-Analysis, 64. $213-226$

Lewis, H. (1971). Shame and guilt in neurosis. Vew York: International Universities Press.

Lewis, H. (1976). Psychic war in men and women. New York: New York University Press.

Lewis, H. (1980). "Narcissistic personality" or "shame-prone" superego mode? Comprehensive Psychotherapy, 1, 59-80.

Lewis, H. (1986). The role of shame in depression. In M. Rutter, C. E. Izard, \& P. B. Read (Eds.), Depression in young people (pp. 325-339). New York: Guilford.

May, R. (1980). Sex and fantasy. New York: Norton.

Miller, R. S. (1985, August). The nature of embarrassability: Correlates and sex differences. Paper presented at the annual meeting of the Arnerican Psychological Association, Los Angeles.

Modell, A. H. (1984). Self psychology as a psychology of conflict: Comments on the psychoanalysis of the narcissistic personality. In G. H. Pollock \& J. E. Gedo (Eds.), Psychoanalysis: The vilal issues (Vol. 2, pp. 131-148). New York: International Universities Press.

Mormison, A. P. (1983). Shame, the ideal self, and narcissism. Contemporary Psychoanalysis, $19,295-318$

O'Leary, J., \& Wright, F. (1986). Shame and gender issues in pathological narcissism. Psychoanalytic Psychology, 3, 327-339.

Piers, G., \& Singer, M. B. (1953). Shame and guilt: A psychoanalytic and a culturat study. Springfield, IL: Thomas. 
Prosen, M., Clark, D. C., Harrow, M., \& Fawcett, J. (1983). Guilt and conscience in major depressive disorders. American Journal of Psychiatry, 140(7), 839-844.

Radloff, L. S. (1986). Risk factors for depression: What do we learn from them? In J. S. Coyne (Ed.), Essential papers on depression (pp. 403-420). New York: New York University Presis. Raskin, R. N., \& Hall, C. S. (1979). A narcissistic personality inventory. Psychological Repor's, 45,590 .

Raskin, R. N., \& Hall, C. S. (1981). The narcissistic personality inventory: Alternate form reliability and further evidence of construct validity, Journal of Personality Assessment, 45, 159-162.

Reich, A. (1960). Pathologic forms of self-esteem regulation. Psychoanalytic Study of the Child, $15,215-232$.

Tarnower, S., \& Humphries, M. (1969). Depression: A recurring genetic illness more common in females. Diseases of the Nervous System, 30, 601-604.

Wurmser, L. (1981). The mask of shame. Baltimore: Johns Hopkins University Press.

Zung, W. (1965). A self-rating depression scale. Archives of General Psychiatry, 12, 63-70.

Zung, W. (1969). A cross-cultural survey of symptoms in depression. American Jaurnal of Psychiatry, 126(1), 116-121. 